Alain Guy and Philosophical Hispanism:

Reception of Spanish Pbilosophy Abroad

\title{
Alain Guy y el hispanismo filosófico: recepción de la filosofía española en el exterior
}

Santiago Arroyo Serrano

Universidad de Salamanca

sarroyo@usal.es

DOI: https://doi.org/10.15366/bp2021.27.026

Bajo Palabra. II Época. № 27. Pgs: 501-516

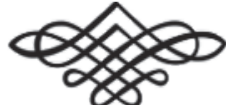


Recibido: 31/03/2021

Aprobado: 07/05/2021

\section{Resumen}

El hispanista filósofo francés Alain Guy dedicó su vida y obra a luchar contra la visión histórica que menospreciaba la filosofía española e iberoamericana, estableciendo un vínculo que va más allá de lo filosófico con los pensadores, poniendo a dialogar la filosofía española con la europea, y desarrollando una fundamental labor investigadora en el Equipe de Philosophie Ibérique de Toulouse, que lo convirtió en uno de los más importantes difusores de la filosofía en español a nivel internacional.

Palabras clave: Filosofia Española, Hispanismo Francés, Historiografia, España, Francia.

\section{Abstract}

The Hispanist French philosopher Alain Guy dedicated his life and work to fighting against the historical vision that despised Spanish and Ibero-American philosophy, establishing a link beyond the philosophical matters with thinkers, putting Spanish and European philosophy in dialogue, and developing a fundamental research work in the Equipe de Philosophie Ibérique de Toulouse, which led him to be one of the most important diffusers of philosophy in Spanish internationally.

Keywords: Spanish Philosophy, French Hispanism, Historiography, Spain, France. 


\section{El punto de partida: Unamuno, la filosofía española y el hispanismo francés}

El hisPanista FILÓSOfo fRANCÉs Alain GuY situó su punto de partida en remediar aquello que alegó Unamuno sobre el hispanismo francés: "pero lo que no a pocos españoles más nos duele es que para una parte de esos hispanistas franceses España parece que se acabó en el siglo XVII o a lo sumo en el XviII; la literatura española contemporánea no existe para ellos. Y por lo que hace a la actual, no creo que la española tenga mucho que envidiar a la francesa" ${ }^{1}$.

Unamuno defendió también que "nuestra actual literatura será más pobre que la francesa, no lo niego, pero es menos monótona, menos gris, más briosa y sobre todo mucho más sincera" ${ }^{2}$, rescatando en su planteamiento sobre el hispanismo francés la vieja cuestión de que África comenzaba en los Pirineos, a lo que Unamuno, con su fina ironía, replicaba que "tal frase no debe ofendernos, pues lo mismo da ser africano que otra cosa y habida cuenta de que africanos fueron, entre otros altísimos espíritus, San Cipriano, Tertuliano y San Agustín, vale más ser africano de primeras que europeo de segundas" 3 .

Indicaba que "el que se quiera meter en África, a estudiarla o a influir en ella, debe empezar por esforzarse en penetrar en el alma africana" ${ }^{4}$, reflexionando sobre las visiones de los hispanistas pues

aquí tenemos una desgracia por lo que respecta a los franceses que de nosotros se ocupan y es que cuando nos conocen, saben nuestra lengua y nos han estudiado, son eruditos, o profesores o universitarios sin acción sobre el gran público francés y a las veces sin la brillantez literaria que para imponerse hace falta, o si son escritores y literatos de renombre, de esos cuyos juicios se hacen públicos, son como Barrés, pongo por caso, que ha escrito sobre España de la manera más fantástica y más fuera de sentido. No le supera en esto más que aquel farceur que se llamó Jean Lorrain, y que escribió los mayores disparates sobre España. ${ }^{5}$

Achaca el problema de los españoles para tener renombre y ser reconocidos en el campo filosófico a ellos mismos, que no han sabido valorarse, ya sea por ignorancia o por mala fe:

\footnotetext{
${ }^{1}$ Unamuno, M. de, De Patriotismo espiritual. Artículos en "La Nación" de Buenos Aires (1901-1914), Salamanca, Ed. de la Universidad de Salamanca, 1997, p. 150.

2 Idem.

3 Ibid., p. 151.

4 Idem.

5 Idem.
} 
hay que decir toda la verdad y es que de mucho de esto tenemos la culpa los españoles mismos. No pocos de esos escritores franceses han sido inducidos a error y mantenidos y corroborados en su fantástica visión de una España contra-hecha por españoles. Y esto lo hacen algunos por ignorancia, otros por mala fe, sin que falte quien lo haga — sobre todo si es de ciertas regiones- por odio a España. Porque podrán ser muchos y grandes los desatinos que sobre España hayan hecho correr escritores extranjeros, y en especial franceses - los ingleses nos conocen mejor- $\frac{6}{6}$, pero no son menos los que han hecho correr escritores españoles y en especial catalanes. ${ }^{6}$

Como ya anticipara Unamuno "desde hace algunos años se ha despertado en Francia, y sobre todo en el medio día de ella, una gran afición por los estudios de lengua, de historia y de literatura españolas. Las universidades de Tolosa y de Burdeos son los dos principales focos de este movimiento hispanista francés. Pero, cabe preguntar, ¿han hecho de veras esfuerzos por penetrar en nuestro espíritu?" 7.

Alain Guy pretende con su proyecto de hispanismo filosófico en Francia solucionar este problema frente a lo que Unamuno considera "triste, pero cada cual lucha por conservar y dar a conocer y expansionar su propia personalidad y le duele

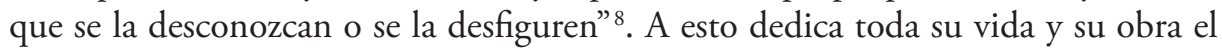
hispanista filósofo y, paradójicamente, tiene que fortalecer los valores filosóficos y descubrir talentos desde su cátedra francesa, lo que lo hace merecedor de la etiqueta de líder dentro del hispanismo filosófico sin ser originario de España.

Parece que el propio Unamuno describe a Guy cuando dice "que no cabe generalizar y que entre esos hispanistas los hay de toda laya; muchos de ellos muy profundos conocedores de nuestras cosas, libres de tradicionales prejuicios — que han sido mutuos - y con firme propósito de penetrar en los más privativo de nuestra alma nacional" 9 .

\section{Los problemas del hispanismo filosófico}

En esta línea establecida en Toulouse por Alain Guy, Antonio Heredia se pregunta qué es el hispanismo filosófico: “¿Se trata de un movimiento reivindicativo de muy complejas resonancias o de una disciplina puramente científica?" ${ }^{10}$. Ya po-

\footnotetext{
${ }^{6}$ Idem.

7 Ibid., p. 149.

8 Ibid., p. 151.

9 Ibid., p. 149.

${ }^{10}$ Heredia Soriano, A., "Hispanismo filosófico: problemas de su constitución”, en El reto europeo: identidades culturales en el cambio de siglo, Madrid, Trotta y AHF, 1994, p. 136.
} 
demos afirmar que es una disciplina que forma parte de las ciencias histórico-filosóficas, aunque es necesario ampliar la perspectiva pues

el hispanismo filosófico debe resolver hoy ante todo su estatuto como disciplina, preguntándose por el lugar que le corresponde ocupar como tal área de conocimiento en el conjunto de las ciencias histórico-filosóficas. Ello implica necesariamente la pregunta por su objeto específico de estudio, dilucidando su particularidad en el orden espacio-temporal y lingüístico y en otros órdenes complementarios. Es evidente que mientras no se tenga una cierta configuración del objeto que se busca; mientras no se llegue a definirlo y caracterizarlo como una realidad histórica frente a otros objetos análogos, no podremos hablar de ciencia alguna; y la cosa no es fácil en nuestro caso, pues no se trata ya de identificar ninguna filosofía particular dentro del mundo hispánico: peruana, argentina, mexicana, española, etc. Eso ya está hecho, de lo que se trata es de ampliar la perspectiva a la filosofía hispánica sin más. ${ }^{11}$

Sobre los hispanistas y la desconfianza respecto a ellos, señala Antonio Heredia que "el término 'hispanismo' fue acuñado entre los siglos XVIII y XIX para designar un fenómeno ante todo idiomático: la presencia en lenguas foráneas de giros, formas, expresiones y vocablos de origen hispánico procedentes en especial de una de las lenguas hispánicas por excelencia, el castellano o español" ${ }^{12}$. Esto explica ese recelo, ya que

los hispanistas europeos y norteamericanos eran mirados en Espańa generalmente con prevención, suponiéndoles — por el mero hecho de no pertenecer a nuestro mundo-incapaces de llenar convenientemente su oficio. En realidad todos se observaban por lo común con mutua desconfianza e incomprensión. A mayor abundamiento, el campo temático de trabajo aparecía muy recortado y a la vez escasamente diferenciado. Había, sí, áreas muy cultivadas [...]; incluso algunas ramas especiales, como el orientalismo hispano, el derecho o la mística, fueron objeto de atención notable y sostenida. Pero aparte de que el punto de vista adoptado fue sintético por lo común, buscando la descripción de grandes bloques o conjuntos de sentido panorámico, en detrimento de la función escrutadora y analítica que conlleva toda investigación, quedaron casi fuera de su punto de mira aspectos tan esenciales de nuestra cultura como el pensamiento y la filosofía. La misma configuración teórica, instrumental y espacio-temporal del hispanismo, en tanto que rama eminentemente historiográfica, no pudo menos que adolecer de falta de autoconciencia y definición. ${ }^{13}$

En este marco de referencia es donde el profesor de Toulouse lleva a cabo su proyecto, en el que, para evitar esa prevención de los investigadores españoles, establece un vínculo directo y estrecho con los filósofos y filósofas nacionales,

\footnotetext{
${ }^{11}$ Ibid., p. 137.

12 Ibid., p. 133.

13 Ibid., p. 134.
} 
con el fin de complementar sustancialmente una rama que el hispanismo había dejado fuera al considerar la filosofía y el pensamiento como elementos residuales: el hispanismo filosófico, del que Alain Guy fue un verdadero pionero, pues "varias son las condiciones que han posibilitado la consolidación del hispanismo en la hora actual. Entre ellas destacamos en primer lugar el redescubrimiento de la tradición como alma nutricia de la creatividad, originalidad e identidad de los pueblos y los individuos, como condiciones para consolidar el hispanismo con una tradición previa" ${ }^{14}$.

\section{El hispanismo filosófico en España y en Francia: interior y exterior}

El particular interés POR lo hispánico en Francia ha respondido históricamente a fenómenos de moda o a la fascinación expresada por algunos intelectuales. A cada lado del Pirineo, individualidades brillantes siempre mantuvieron relaciones personales basadas en la admiración amistosa.

Por hispanismo filosófico francés entendemos cuando "los hispanistas franceses se interesan por los pensadores españoles contemporáneos, en el sentido amplio de la palabra" ${ }^{15}$. Respecto a la recepción de la filosofía en Francia, Guy defiende que "todo balance es difícil en una materia tan compleja como la recepción de la filosofía espańola por los franceses. [...] poco a poco se va disipando el estúpido prejuicio antiespañol de la leyenda negra, según el cual no había filosofía española original o creadora. ¡Ojalá que la curiosidad francesa para con el pensamiento ibérico aumente y que el público culto tome cada vez mayor contacto con las elaboraciones filosóficas de la Península, que están a la altura europea y mundial!" ${ }^{16}$.

Cuando en los ańos del franquismo se imponía un riguroso control ideológico de las actividades intelectuales, existían en Francia fecundas corrientes reformadoras que reorganizaron la ciencia histórica, proporcionando atractivos modelos y nuevas herramientas metodológicas. Las condiciones de la investigación científica se formalizaron tempranamente en Francia y se reservó a los estudios hispánicos un papel importante a través de equipos universitarios, centros integrados o asociados con el CNRS (Centre National de la Recherche Scientifique), revistas de nivel internacional y una institución como la Casa de Velázquez en Madrid, emblema de la presencia francesa en el terreno cultural.

\footnotetext{
${ }_{14}$ Ibid., p. 135.

15 Guy, A., "Los hispanistas franceses actuales, investigadores de la filosofía española de ayer y de hoy", en Arbor, Madrid, n.o 400 (1979), p. 77.

${ }^{16}$ Ibid., pp. 82-83.
} 
Gerardo Bolado Ochoa, al analizar la filosofía española del siglo xx y realizar una aproximación a la Historia de la filosofía española en la que repasa su marco general, hoy parte importante del hispanismo filosófico, señala que

este periodo, entre los filósofos historiadores y los historiadores filósofos, ha predominado una historiografía académica ciega al contexto socio histórico y cultural español, al carácter narrativo de la filosofía y de su historia, y a la existencia de una creciente masa crítica en este campo de la Historia de la Filosofía Espańola; un academicismo que ha narrado la Historia de la Filosofía al margen de su desarrollo real en la sociedad espańola. ${ }^{17}$

Pero la sistematizada apropiación por la comunidad científica española de los campos de su propia historia marcó, sin lugar a duda, una nueva etapa. Constituyen el testimonio de este renacimiento un florecer de brillantes trabajos monográficos y programas de investigación colectiva. Las relaciones entre historiadores franceses y españoles ya se sitúan en el plano de la colaboración y del intercambio científico.

En relación con el hispanismo filosófico francés, es fundamental la aportación historiográfica del Equipe de Philosophie Ibérique, el grupo hispanista de la Universidad de Toulouse, fundado en 1967 y dirigido por Alain Guy, que permitió que sus obras, fruto de sus investigaciones, pudieran dialogar y ser referencia para la investigación filosófica en España, pues, según Martín González Fernández

la aportación de sus trabajos es muy valiosa y estos son, sin duda, un buen complemento — por lo que a la filosofía española se refiere— de la obra de Abellán. [...] Alain Guy y los miembros del Equipe de philosophie ibérique [...] han demostrado ser buenos conocedores de nuestra cultura y nuestro pensamiento. Aún más, hay que agradecerles su puntual advertencia, sin que ello signifique negar las "peculiaridades" de nuestro pensamiento (en el sentido de Abellán), de que no se puede "descontextualizar" este del "marco intelectual" europeo y que hay que analizarlo en su diálogo permanente con él. ${ }^{18}$

La insistencia en comunicar y poner a dialogar la filosofía española con Europa va a ser uno de los elementos claves de toda la obra de Alain Guy. En la base de su interés por la filosofía española, emerge la figura de su maestro, Jacques Chevalier, que en su Historia del pensamiento incluía filósofos españoles cuando hasta el momento otras historias se habían dedicado, más que a valorar la filosofía, a silenciar algunas de las influencias más importantes de la filosofía española. Esto sería un aliciente para la curiosidad de Guy, que libró una batalla por recuperar

17 Bolado Ochoa, G., Transición y recepción: La Filosofía Española en el último tercio del siglo xx, Santander, Sociedad Menéndez Pelayo / Centro Asociado a la UNED en Cantabria, 2001.

${ }^{18}$ González Fernández, M., "La labor historiográfica del 'Equipe de Philosophie Ibérique’ de la Universidad de Toulouse-Le Mirail”, en Ágora. Papeles de Filosofía, 2 (1982), p. 163. 
y mediar con Francia para dar a conocer el pensamiento español y, lo que es más importante, ponerlo a dialogar, a través de un comparatismo riguroso y seguro, con los principales filósofos europeos.

Además, Alain Guy encontró en Salamanca un lugar privilegiado para el inicio y el fin de su proyecto: el inicio, porque decidió realizar sus tesis de doctorado sobre el pensamiento filosófico de Fray Luis de León y las líneas de especulación filosófica y teológica en la Universidad de Salamanca del siglo xvi; el fin, porque, quizás como algo providencial, Reine Guy, su esposa, decidió que su archivo, su alma y sus relaciones personales, académicas y familiares fueran a parar a esta ciudad, con la donación del patrimonio documental del hispanista filósofo francés a la Universidad de Salamanca.

Para estudiar a los autores anteriores al siglo xx Alain Guy se basó en las importantes bibliotecas francesas y alguna española, y para el siglo XX tuvo como referencia a los propios autores, desde sus cátedras y con sus publicaciones más recientes. Uno de los grandes méritos de Alain Guy es que, en su trabajo sobre el siglo $\mathrm{xx}$, comienza desde cero, apenas tenía referencias previas, ya que las dos obras de referencia que existían cuando se publicó el primer volumen de la importante obra biobibliográfica de Gonzalo Díaz iniciada en 1980 eran la Historia crítica del pensamiento español de José Luis Abellán y la Historia de la Filosofía Española de Guillermo Fraile ${ }^{19}$, documentación a la cual no tuvo acceso desde Francia.

Como hispanista, reflexiona sobre el verdadero valor de lo hispánico atendiendo a la recepción y proyección de la filosofía española. Se interesa por la forma en que España y América Latina son vistas por pensadores franceses y viceversa, y por la difusión de la filosofía española en Francia y la de la filosofía francesa en España.

Su afán por abrir horizontes lo convierte también en uno de los primeros autores en estudiar pensadores y pensadoras españoles en el exilio.

Así, recupera Guy el nuevo significado de los textos históricos como colecciones de signos "con el fin de transmitir ciertos significados a una audiencia; además, las interpretaciones textuales son textos que pretenden producir actos de comprensión semejantes a aquellos que se supone tuvieran tanto el autor como la audiencia coetánea del texto. La necesidad de una interpretación que permita recuperar de nuevo el significado de los textos históricos añade un nuevo apoyo, aunque indirecto, a la tesis general del libro que la historia de la filosofía debe hacer filosóficamente" ${ }^{20}$.

19 Véase Abellán, J. L., Historia crítica del pensamiento español, Madrid, Espasa-Calpe, 1979-1991 y Fraile, G. y Urdanoz, T., Historia de la filosofía española, Madrid, Biblioteca de Autores Manchegos, 1971.

${ }^{20}$ Cañas Fernández, J. L., "Sobre historiografía filosófica y filosofía de la historia de la filosofía", en Anales del Seminario de Historia de la Filosofía, Universidad Complutense de Madrid, n. ${ }^{\circ} 16$ (1999), p. 255. 
Así, en el ámbito del hispanismo filosófico Alain Guy supera su labor de mero estudioso o intelectual y se convierte en un filósofo historiador desde su posición de hispanista filósofo, que no solo va a investigar sino que será el fundamento para desplegar su propia filosofía, con su proyecto filosófico a través de las grandes figuras hispánicas gracias al que acerca la filosofía española a Europa y despierta vocaciones en otros hispanistas del ámbito de la filosofía.

Es de suyo importante, pues cualquier historia de la historiografía de la filosofía española, como historia disciplinar de la filosofía española e iberoamericana, contaba, pues, con los antecedentes del hispanismo francés y la institucionalización del equipo de Alain Guy por su importante aportación a la disciplina, como han reconocido los principales historiadores de la filosofía espańola. Todo ello desde un pensamiento singular como filósofo orientado a la vida e historiador "filosofante" que encontró en la tradición del pensamiento español una vía para la resolución de los problemas de la humanidad, buscando la aportación española a la filosofía universal.

Por lo tanto, el gran objetivo del hispanismo filosófico exterior, y más concretamente del hispanismo francés, sería elaborar una historia general de la filosofía española dirigida al público extranjero, lo que significaría utilizar las categorías no nacionales, sin reducirse a metodologías. A la hora de buscar la identidad política-filosófica en la historia no todo vale, ya que como señala Heredia

el hispanismo filosófico debería defender su identidad histórico-filosófica como unidad de integración; y defenderla también con el nombre. Claro que nuestros filósofos son pensadores, pero también [...] que no todos nuestros pensadores son filósofos; y el "hispanismo filosófico" quiere decir interés desde y por la filosofía. De lo contrario se corre el riesgo del "todo vale", confundiéndose con una historia general de la civilización o de la cultura absolutamente necesaria, importante, pero que no es el objeto de nuestra ocupación. ${ }^{21}$

Aquí conviene recordar y reivindicar los valores y la lucha de Alain Guy, así como la integración socioacadémica, la consolidación y la madurez del hispanismo, que él considera una rama historiográfica adulta. Además, impulsó y participó de la realidad institucional —se implicó, por ejemplo, en la Asociación de Hispanismo Filosófico y en su Revista—, en un momento en que la emergencia de una figura con un liderazgo esencial es un ejemplo de otros que

van surgiendo con fuerza por todas partes, dando a luz publicaciones de buena factura y tomando iniciativas de diversa índole dirigidas a consolidar una tarea tan necesaria en

\footnotetext{
${ }^{21}$ Heredia Soriano, A., "Hispanismo filosófico: problemas de su constitución", en El reto europeo: identidades culturales en el cambio de siglo, op. cit., p. 139.
} 
el conjunto de las ciencias histórico-filosóficas... No obstante, a pesar del panorama prometedor y del buen clima reinante en muchos círculos, me atrevo a afirmar que el hispanismo filosófico está aun muy lejos de formar esa realidad asociativa y orgánica, integrada y dinámica, imprescindible para constituirlo en rama historiográfica adulta y disponerlo a rendir todo el fruto que de él tienen derecho a esperar, no ya la historia particular de los pueblos hispánicos en sí y en sus relaciones con los demás pueblos, sino la historia de la filosofía sin más. ${ }^{22}$

Con su propuesta, el profesor de Toulouse trabaja para fortalecer ese organismo, profundizando en todas sus obras en la influencia de Francia en España y en la historia del hispanismo filosófico francés, como las motivaciones para los franceses por investigar España.

Fue el primer hispanista filósofo de profesión sensu stricto, en sentido amplio de la palabra. Dedicó su carrera a la investigación de la filosofía espańola, y su hispanismo filosófico tuvo una misión fundamental: desplegar el carácter de un profundo humanismo cristiano abierto a través de dos grandes líneas de trabajo: una como historiador, para poder poner en su lugar correspondiente a los filósofos españoles; otra como filósofo, con un proyecto intelectual ecléctico que buscaba proyectar los valores de un humanismo hispanoeuropeo conectando lo mejor de la tradición clásica con la renovación del renacimiento español, ampliándolo posteriormente a América Latina.

\section{Alain Guy, referente del hispanismo filosófico mundial}

Por tOdo Lo ANTERior, Abellán consagra a Alain Guy, en su artículo en Ínsula ${ }^{23}$, como el gran hispanista filósofo y un puente para el diálogo de España con Europa. El propio Abellán afirma — creemos que gracias a la labor de su amigo en Toulouse- que "Hoy nadie puede decir aquella famosa frase de Victor Delbos: para conocer la filosofía se deben poseer todas las lenguas menos el español" 24 .

Antonio Jiménez, por su parte, afirma que "el hispanismo tolosano forjado en torno a su figura, con su espíritu abierto y tolerante, ha jugado un gran papel en la difusión del pensamiento ibérico e iberoamericano fuera de nuestras fronteras" 25 .

\footnotetext{
22 Ibid., pp. 141-142.

23 Abellán, J. L., "Alain Guy o el hispanismo en filosofía”, en Ínsula, n.o 349 (1975), pp. 14-15.

24 Abellán, J. L., "El pensamiento español actual: estado de la cuestión", en Bajo Palabra. Revista de Filosofía, II Época, n.o 4 (2009), pp. 335-344.

25 Jiménez García, A., “Alain Guy y el hispanismo tolosano”, en Romero Baró, J. M. (coord.): Homenaje a Alain Guy, Barcelona, Universidad de Barcelona, 2005, p. 142.
} 
José Luis Mora, al explicar los antecedentes del nacimiento del Seminario de Historia de la Filosofía Española e Iberoamericana y de los elementos que propiciaron su creación, afirma que uno de los nombres propios fundamentales era "Alain Guy, muy vinculado a la ciudad de Salamanca y a su tradición filosófica y mística a través de Domínguez Berrueta, gran difusor de la filosofía española desde su cátedra en Toulouse" 26 . Señala Mora sobre el papel de Guy que "hablamos de un gran representante del hispanismo francés, cuya humanidad transmitía siempre respeto por la memoria de sus maestros y una voluntad muy clara en defensa de sus compromisos. No ha pasado desapercibido que ambas virtudes constituyeran un ejemplo para la España de los setenta, dubitativa, desconocedora de su propia tradición cuando no sumida en el desprecio por la misma" 27 . Para Mora, "Alain Guy jugó en aquellos años el papel de garante, un puente que permitía recuperar lo que habíamos abandonado o lo que habíamos perdido" ${ }^{28}$. Resaltando sus posiciones conciliadoras, "mostraba una cara bien diferente a las posturas de confrontación propias de la filosofía académica española de aquellos años en la que nos habíamos formado quienes pasábamos por las aulas en el cambio de década hacía los setenta" 29 , así "su posición era la del historiador o la del sociólogo del conocimiento que nos recordaba a los jóvenes de entonces una cosa evidente: que santo Tomás murió sin saber que existiría el nacionalcatolicismo" ${ }^{30}$. Se convirtió entonces en "un puente cruzado que evitó aislamientos y creó contactos entre intelectuales que habían militado en la discrepancia con el régimen (y en muchos casos en oposición abierta)" ${ }^{31}$.

Una de las reflexiones de José Luis Mora define la metodología que Alain Guy y su equipo de hispanismo filosófico consolidó y utilizó en Toulouse, en Salamanca y en diferentes eventos institucionales: fue la del intercambio intelectual, la de los nuevos métodos de investigación, "El debate, el intercambio de información, la atención a preocupaciones muy diversas dentro del ámbito filosófico han permitido a este grupo desvelar nombres, temas, problemas y soluciones en la historia de España y los países que comparten lengua y en buena medida tradiciones que han sido recuperados para la filosofía y para las culturas que le sirven de marco" 32 .

Alain Guy venía prendado de un hispanismo que por cuestiones técnicas, sociales y existenciales no había podido culminar, pero el avance del siglo xx y el fin de

\footnotetext{
${ }^{26}$ Mora García, J. L., "El Seminario de Historia de la Filosofia Española e Iberoamericana: modernidad y tradición en Salamanca”, en La Ciudad de Dios, El Escorial, CCXV (2002), p. 995.

27 Ibid., p. 996.

28 Idem.

29 Idem.

30 Idem.

31 Idem.

32 Ibid., p. 1041.
} 
la dictadura le permitieron finalizar una obra única para el hispanismo filosófico en el exterior, bien aceptado en el interior.

El hispanista filósofo francés, según Gustavo Bueno, va más allá de los prejuicios para superarlos; despliega una filosofía de palabras de acción, progresista, en "estos pensamientos objetivados, expresados como pensamientos extrasomáticos, sobre todo en el lenguaje escrito, [...] aquellos que se tienen en cuenta cuando se habla de pensamiento español, en su confrontación con el pensamiento francés, el pensamiento alemán o el pensamiento chino" ${ }^{33}$, porque "este pensamiento público no se considera tanto en cuanto ha sido expresado por agentes individuales, sino en tanto está virtualmente actuando, en función apelativa, sobre otros ciudadanos o grupos, representando algún contenido determinado y estructurado" ${ }^{34}$.

Desde la perspectiva metodológica, Antonio Heredia sostiene que "[...] la historia no es solamente acción, sino expresión. Por tanto, quien escribe bien la historia, hace también historia" ${ }^{35}$. Y el profesor Luis Jiménez Moreno piensa que "la docencia intensifica la reflexión sobre las cuestiones que se $\operatorname{tratan}^{\text {" } 36}$, que bien se podría aplicar a la filosofía del gran hispanista y a la docencia de temas de filosofía española e iberoamericana que llevó a cabo en Toulouse a partir del año 1954.

Heredia, en las conclusiones del I Seminario de Historia de la Filosofía Espańola, celebrado en 1978 en Salamanca, dedica un agradecimiento específico "al prestigioso grupo de Toulouse, encabezado por el profesor Alain Guy, que nos ha acompañado durante estas jornadas, y no solo por haber estado aquí presente, sino por su estimable y entusiasta labor en pro de la difusión internacional de la filosofía española. Ahora bien, el énfasis que señalamos respecto de su importancia externa no debe hacernos olvidar a su vez su importancia interna para los estudios filosóficos peninsulares, pues — dado el secular complejo de inferioridad español hacia nuestras propias producciones - el reconocimiento de nuestra labor por un prestigioso grupo extranjero es un factor esencial en el fortalecimiento interior de la disciplina que nos ocupa" ${ }^{37}$.

El fundador del Seminario de Salamanca sostiene que "no fue un hispanista distante, sino comprometido; comprometido con el buen nombre de España y su verdad histórica" ${ }^{38}$. Este compromiso le permitió acceder a un papel central y pro-

33 Bueno Sánchez, G., "La esencia del pensamiento español", en El Basilisco, Oviedo, n. o 26 (1999), p. 70.

${ }^{34}$ Idem.

35 Heredia Soriano, A., "José Luis Abellán en la tradición historiográfica de la filosofía española”, en Cuadernos Salmantinos de Filosofia, n. ${ }^{\circ} 6$ (1979), p. 467.

36 Jiménez Moreno, L., Práctica del saber en filósofos españoles, Barcelona, Anthropos, 1991, p. 9.

37 Heredia Soriano, A. (dir.), Actas del I Seminario de Historia de la Filosofia Española, Salamanca, Ed. de la Universidad de Salamanca, 1978, p. 299.

${ }^{38}$ Heredia Soriano, A., "Alain Guy (1918-1998), in memoriam", en Anuario de Historia de la Iglesia, 8 (1999), p. 434. 
tagonista en cuanto a la difusión y audiencia de sus textos, no solo en Francia, sino en todo el ámbito hispánico.

Como plantea Jiménez Moreno, "la trayectoria de un filósofo comprende dos condiciones: la adquisición de un determinado capital cultural y la inversión del mismo en la comunicación pública" ${ }^{39}$. Según su perspectiva, la carrera de Alain Guy como hispanista filósofo se habría desarrollado con una autonomía creativa considerable, siendo clara su consagración institucional dentro y fuera de España y al mismo tiempo su consagración intelectual.

Pudo desarrollar ampliamente su hispanismo filosófico como líder del grupo europeo de hispanistas, lo que le permitió "relacionarse con los centros de vanguardia en los que se reúnen los colegas y participar, a ser posible exitosamente, en los debates" ${ }^{40}$, y es que fue el nodo del hispanismo filosófico mundial porque "solo aquellos que entran en contacto con un grupo intelectualmente bien situado desarrollan los saberes que permiten atraer el centro de atención" ${ }^{41}$. Este grupo fue esencial para consolidar muchos de los proyectos que aún perviven hoy.

Todo ello sin dejar de lado el necesario compromiso político de la filosofía hispánica porque

el filósofo ha marcado objetivos futuros a partir de un juicio sobre el significado del pasado y/o presente: es la posición del profeta. Por otro lado, un filósofo puede ofrecer una visión general sobre el mundo cuyo objetivo es dar sentido a nuestro lugar en el universo: es la posición del sabio. En fin, ser filósofo puede consistir en transmitir la doctrina de otros filósofos, actividad esta que ocupa a los profesores de Filosofía. ${ }^{42}$

Por tanto, la visión de Alain Guy fue dinámica, sin entrar en luchas, sin encontrar ningún año negro o estéril de la filosofía española, lo que le valió el prestigio tanto en Francia y Europa como en España, con una reflexión abierta que no se desentiende de otras cuestiones externas a la filosofía que forman parte de la teoría misma. Así, una de las principales características de su hispanismo filosófico es vivir a caballo entre la filosofía mundana y poder comunicarse con los filósofos y al mismo tiempo con la academia, dominando la historia de la filosofía y sus categorías universales.

Su posición institucional alcanzó a públicos académicos y extraacadémicos, tanto en Francia y Europa como en Espańa, de manera que el espectro de sus relaciones fue amplísimo, manteniendo a lo largo de su trayectoria una posición central en el hispanismo filosófico internacional, que no ha sido ocupada desde su fallecimiento por ningún otro filósofo o grupo, ni en Francia ni en ningún otro país del mundo.

\footnotetext{
9 Jiménez Moreno, L., Práctica del saber en filósofos españoles, op. cit., p. 36.

40 Ibid., p. 37.

${ }^{41}$ Ibid., p. 38

42 Ibid., p. 46
} 


\section{REFERENCIAS BIBLIOGRÁFICAS}

Abellán, J. L., "Alain Guy o el hispanismo en filosofía", en Ínsula, n.o 349 (1975).

__, Historia critica del pensamiento español, Madrid, Espasa-Calpe, 1979-1991.

___, "El pensamiento español actual: estado de la cuestión”, en Bajo Palabra. Revista de Filosofía, II Época, n. ${ }^{\circ}$ (2009), pp. 335-344.

Bolado Ochoa, G., Transición y recepción: La Filosofía Española en el último tercio del siglo xx, Santander, Sociedad Menéndez Pelayo / Centro Asociado a la UNED en Cantabria, 2001.

Bueno SÁnchez, G., "La esencia del pensamiento español", en El Basilisco, Oviedo, n. 26 (1999), pp. 67-80.

Cañas Fernández, J. L., "Sobre historiografía filosófica y filosofía de la historia de la filosofía", en Anales del Seminario de Historia de la Filosofía, Universidad Complutense de Madrid, n. 16 (1999), pp. 249-257.

Fraile, G. y Urdanoz, T., Historia de la filosofía española, Madrid, Biblioteca de Autores Manchegos, 1971.

González Fernández, M., "La labor historiográfica del 'Equipe de Philosophie Ibérique' de la Universidad de Toulouse-Le Mirail”, en Ágora. Papeles de Filosofía, 2 (1982), pp. 163-169.

GuY, A., "Los hispanistas franceses actuales, investigadores de la filosofía española de ayer y de hoy", en Arbor, Madrid, n.o 400 (1979).

Heredia Soriano, A. (dir.), Actas del I Seminario de Historia de la Filosofía Española, Salamanca, Ed. de la Universidad de Salamanca, 1978.

—_, "José Luis Abellán en la tradición historiográfica de la filosofía española", en Cuadernos Salmantinos de Filosofía, n. 6 (1979), pp. 463-467. doi: https://doi.org/10.36576/summa.639.

_- "Hispanismo filosófico: problemas de su constitución", en El reto europeo: identidades culturales en el cambio de siglo, Madrid, Trotta y AHF, 1994, pp. 133-142.

_- "Alain Guy (1918-1998), in memoriam", en Anuario de Historia de la Iglesia, 8 (1999), pp. 432-434. 
Jiménez García, A., "Alain Guy y el hispanismo tolosano", en Romero Baró, J. M. (coord.): Homenaje a Alain Guy, Barcelona, Universidad de Barcelona, 2005, pp. 129-142.

Jiménez Moreno, L., Práctica del saber en filósofos españoles, Barcelona, Anthropos, 1991.

Mora García, J. L., "El Seminario de Historia de la Filosofía Española e Iberoamericana: modernidad y tradición en Salamanca”, en La Ciudad de Dios, El Escorial, CCXV (2002), pp. 987-1041.

Unamuno, M. de, De Patriotismo espiritual. Artículos en "La Nación" de Buenos Aires (1901-1914), Salamanca, Ed. de la Universidad de Salamanca, 1997.

DOI: https://doi.org/10.15366/bp2021.27.026

Bajo Palabra. II Época. № 27. Pgs: 501-516 
